\title{
Determination of Neospora caninum and Toxoplasma gondii in aborted bovine foetuses by duplex PCR, immunohistochemistry and immunofluorescence methods
}

\author{
MUSTAFA OZKARACA, BUNYAMIN IREHAN*, AYSE PARMAKSIZ**, \\ AYSEL ITIK EKINCI*, SELIM COMAKLI
}

\author{
Department of Pathology, Faculty of Veterinary Medicine, Atatürk University, 25240 Erzurum, Turkey \\ *Veterinary Control Institute, Elazığ, Turkey \\ **Veterinary Control Institute, Istanbul, Turkey
}

Ozkaraca M., Irehan B., Parmaksiz A., Ekinci A. I., Comakli S.

Determination of Neospora caninum and Toxoplasma gondii in aborted bovine foetuses by duplex PCR, immunohistochemistry and immunofluorescence methods

\section{Summary}

This study was aimed at determining the existence of Neospora caninum and Toxoplasma gondii in aborted bovine foetuses. In this research, 102 bovine foetuses were examined by duplex PCR, immunohistochemistry and immunofluorescence to determine the presence of $\mathrm{N}$. caninum and $\mathrm{T}$. gondii. None of the aborted bovine foetuses were shown to have T. gondii, but $\mathbf{N}$. caninum was detected in 26 foetuses $(25.49 \%)$ by duplex PCR, in $18(17.64 \%)$ by immunohistochemistry and in 8 (7.84\%) by immunofluorescence. Moreover, 16 livers, 13 kidneys, 12 spleens, 8 thymuses and 5 brains of the 18 foetuses examined by immunohistochemistry showed immunopositivity. Positive staining was found in the spleen of eight foetuses by the immunofluorescence method. In this study, immunohistochemistry was shown to be superior to immunofluorescence in terms of diagnosis. Although immunofluorescence has the advantage of being the easiest to use in practice, it makes diagnosis more difficult because of its non-specific staining.

Keywords: Neospora caninum, Toxoplasma gondii, duplex PCR, immunohistochemistry, immunofluorescence

Neospora caninum, which causes abortions in bovines, is an obligate intracellular parasite. Dogs are the only known definitive host for $N$. caninum. The parasite has three infectious forms: tachyzoites, bradyzoites and oocysts. While tachyzoites and bradyzoites are found in intermediate hosts, oocytes are present in the faeces of dogs. $(3,15,16,21)$. The effects of the parasite in the tachyzoite form have been detected in many internal organs and tissues of the body, especially the brain, spinal cord, placenta and foetus (17). Bradyzoites are a cystic and slow-generating form of the parasite $(15,16)$, and the oocyst forms are excreted in dog faeces $(7,15,20)$. After the oocytes have been ingested orally by an intermediate host, the sporozoites, released in the intestines, reach the mesenteric lymph nodes, passing through the intestinal mucosa, and from there to other organs via the lymph and blood (24). These tachyzoites proliferate rapidly by dividing inside different cells of the organs and form many tachyzo- ites, which lyse the infected cells. Subsequently, the tachyzoites invade other cells. Then, the tachyzoites are converted into bradyzoites, and the bradyzoites form tissue cysts by a slow proliferative process ( 9 , $30,32,49)$.

Another obligate intracellular parasite, Toxoplasma gondii, also has three forms designated as tachyzoites, bradyzoites and oocysts. The tachyzoite form is an invasive form of the parasite, which multiplies rapidly and is seen during the acute period of infection. Three thousand parasites which are found in the bradyzoite form can stay alive for about six years. The oocyst form of the parasite is found only in felidae faeces. Oocytes released from cat faeces are not immediately infectious, but they get sporulated and become infectious under favourable temperature and humidity. Their biological development resembles that of $N$. caninum $(18,26,28,43,45)$. 
The diagnosis of $N$. caninum and T. gondii has been accomplished by various tests, including immunohistochemistry (IHC), the polymerase chain reaction (PCR), electron microscopy, serological tests, the enzymelinked immunosorbent assay (ELISA), complement fixation, an indirect hemagglutination test, a latex hemagglutination test, the modified agglutination test, the indirect fluorescence antibody test, Sabin-Feldman Dye and Western blot $(16,19,22,25,29,50)$.

Worldwide epidemiological studies related to N. $\mathrm{ca}$ ninum and $T$. gondii have been based mainly on serological tests. It was shown that $N$. caninum detected in cows had $12.5 \%$ serological positivity in England and Wales (14), 36.8\% in Spain (40), 15.5\% in Poland (9), 56.9\% in Argentina (38) and 59\% in Mexico (48). Studies regarding $T$. gondii have been related mostly to sheep. Seropositivity of T. gondii was $7.4-25.2 \%$ in Australia (37), 25.3\% in India (13), 22.9\% in Ethiopia (6), 39\% in Saudi Arabia (2) and $28.4 \%$ in Italy (31).

$N$. caninum results in congenital infections and abortions in cows, but abortions are not observed before the third month of pregnancy. They can occur at any time after the third month of pregnancy, and are most common in the $5^{\text {th }}$ and $7^{\text {th }}$ months of pregnancy $(4,5)$. T. gondii can also lead to abortions, although the effect is less severe $(11,12,46)$.

Overall, the goals of this study were to diagnose the presence of these protozoans in cows by duplex PCR, IHC and immunofluorescence (IF), to determine the distribution of antigens in the organs, and to compare the results of IHC and IF.

\section{Material and methods}

Sampling. The examination material came from the brain, myocardium, liver, lung, kidney, spleen and thymus of 102 aborted bovine foetuses $\left(4^{\text {th }}-7^{\text {th }}\right.$ month) that were brought to the Elazığ Veterinary Control and Research Institute over a 12-month period (January-December 2014). Each organ was evenly receipted (0.2 gram) and diluted with PBS until density was $1 / 10$. The prepared mixture was homogenized in a stomaker for 3 minutes. Thereafter, the parasites were first examined by duplex PCR.

Duplex PCR. DNA extraction was done by a phenol/ chloroform/isoamyl alcohol extraction method from a mixture of brain, myocardium, liver, lung, kidney, spleen and thymus. To detect the nucleic acids of the $N$. caninum and T. gondii in the DNA extracts, the primers of the related regions were chosen from those commonly used. For this purpose, the primer pairs that amplified a $337 \mathrm{bp}$ long strand from the NC5 region for the $N$. caninum ([F] 5' CCCAGTGCGTCCAATCCTGTAAC 3' and [R] 5' CTCGCCAGTCAACCTACGTCTTCT 3') and primer pairs that amplified a $575 \mathrm{bp}$ long strand from the ITS1 region for the T. gondii ([F] 5' TGGCGCCGTTCGTGCCCGAAAT 3' and [R] 5' TGCAITTYGCTGCGKYCTTC 3') were chosen (47).

During multiplex PCR, a mixture of a Qiagen Tag PCR Master Mix Kit (Cat No/ID 201443) was prepared according to the procedure recommended by the manufacturer. In addition, positive controls for $N$. caninum (ATCC Number: 50843D ${ }^{\mathrm{TM}} N$. caninum Nc-1) and T. gondii (from the Refik Saydam Hifzisihha Centre) were used (47). The products obtained from a thermal cycler (Techne TC-PLUS) were run in a $1 \%$ agarose gel at $60-100 \mathrm{~V}$ for 90 minutes. Agarose gels were stained with $0.6 \mathrm{ug} / \mathrm{ml}$ ethidium bromide solution for $20 \mathrm{~min}$. PCR products were visualized with an ultraviolet transilluminator, and molecular weight sizes were determinated by comparison with a 100 base pair (bp) DNA ladder plus. During the visualization of the $1 \%$ agarose gel results, the positivity of the $N$. caninum $337 \mathrm{bp}$ long band of the NC5 gene and the positivity of the T. gondii $575 \mathrm{bp}$ long band of the ITS1 gene were examined.

Immunohistochemistry and immunofluorescence. The tissues detected in a $10 \%$ neutral formalin solution were embedded in paraffin blocks after the routine processes.

IHC was carried out by the streptavidin-biotin complex method (LSAB+ System-HRP; DAKO, Carpinteria, CA, USA). After embedding on glass slides, $5 \mu \mathrm{m}$ tissue sections were washed with xylol and alcohol. The sections were then washed in PBS and incubated in $3 \% \mathrm{H}_{2} \mathrm{O}_{2}$ for 10 minutes to inactivate the endogenous peroxidases. The tissues were treated twice with a retrieval solution for 5 minutes at $500 \mathrm{~W}$ to reveal the antigens. Then, the tissues were washed with PBS and incubated with a $1: 10,000$ dilution of the $N$. caninum primer antibody (Neospora caninum Antiserum, Catalogue No. 210-70-NC, VMRD) and T. gondii primer antibody (Toxoplasma gondii Antiserum, Catalogue No. 210-70-TOX, VMRD) at $37^{\circ} \mathrm{C}$ for 30 minutes. The tissues were washed with PBS at the end of the incubation period and incubated for 15 minutes each in biotinylated antibodies and streptavidin-HRP. The chromogen used was 3, 3'-diaminobenzidine (DAB), and the sections that had been incubated in the chromogen (for about 2 minutes) were washed with distilled water; then, Mayer's hematoxylin staining was applied as a contrast stain. Entellan was dropped on the tissue sections, which were then marked as positive (1) or negative (0) under a light microscope (Nikon, Ni-E).

In the IF method, $8 \mu \mathrm{m}$ thick sections were prepared from frozen sections with a microtome. These sections were incubated in ethyl alcohol for 15 minutes; then, the sections were incubated in a $1: 10,000$ diluted $N$. caninum primer antibody (Neospora caninum Antiserum, Catalogue No: 210-70-NC, VMRD) and T. gondii primer antibody (Toxoplasma gondii Antiserum, Catalogue No: 210-70-TOX, VMRD) at room temperature. At the end of the incubation period, the sections were washed with PBS and covered with 1:400 diluted fluorescent secondary antibodies (Anti-Caprine IgG FITC, Catalogue No. CJ-F-CAPG-10ML, VMRD) at $37^{\circ} \mathrm{C}$ for 30 minutes. Then, the samples were washed with PBS; distilled water: glycerol (1:10) was dropped on them, and they were covered with glass slides. The results were evaluated as positive (1) or negative (2) under a fluorescent microscope (Nikon, Ni-E).

Statistical analysis. To compare the IHC and IF results, the Wilcoxon test, a nonparametric statistical test, was used to evaluate the differences between the two dependent groups. The statistical analyses were accomplished with the SPSS version 15.0 (IBM), and statistical significance was set at $\mathrm{p}<0.001$. 


\section{Results and discussion}

Using duplex PCR, 102 aborted bovine foetuses were examined to reveal the presence of $T$. gondii and $N$. caninum DNA which were extracted from the tissue mixture of homogenized brain, myocardium, liver, lung, kidney, spleen and thymus. Although $T$. gondii

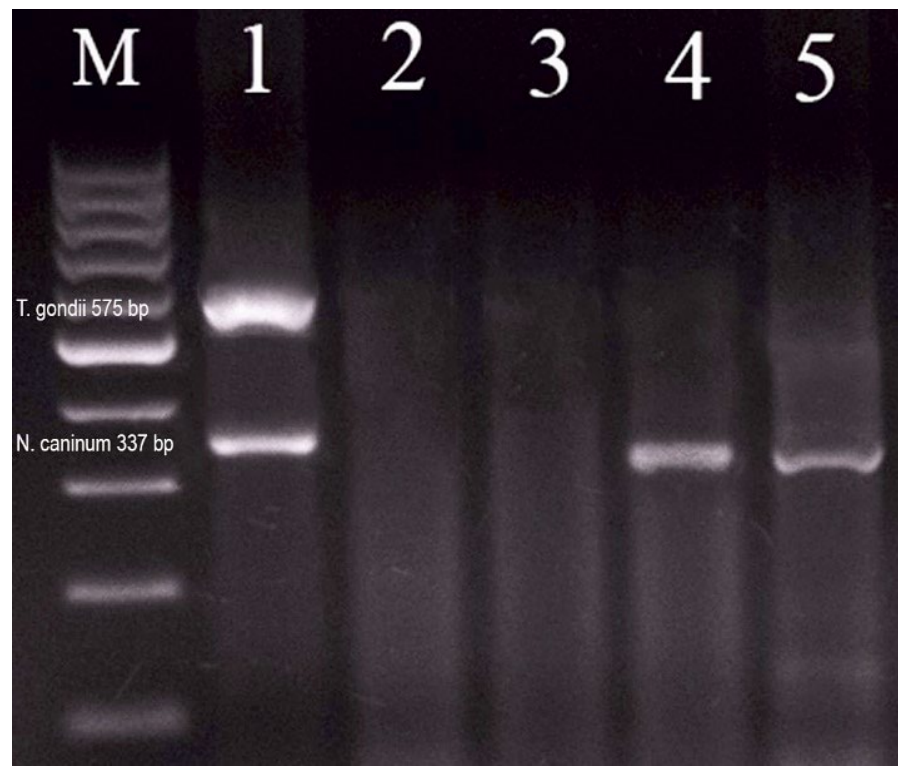

Fig. 1. Dupleks PCR

Explanations: M: 100-base pair (bp) DNA ladder, $1-N$. caninum (337 bp) and T. gondii (575 bp); 2, 3 - negative samples; 4, 5 positive samples

Tab. 1. N. caninum positive samples and distribution according to organs

\begin{tabular}{|c|c|c|c|c|c|c|c|}
\hline Sample & $\begin{array}{c}\text { Liver } \\
\text { IHC/IF }\end{array}$ & $\begin{array}{c}\text { Kidney } \\
\text { IHC/IF }\end{array}$ & $\begin{array}{c}\text { Spleen } \\
\text { IHC/IF }\end{array}$ & $\begin{array}{c}\text { Thymus } \\
\text { IHC/F }\end{array}$ & $\begin{array}{c}\text { Brain } \\
\text { IHC/IF }\end{array}$ & $\begin{array}{c}\text { Myocard } \\
\text { IHC/IF }\end{array}$ & $\begin{array}{c}\text { Lung } \\
\text { IHC/IF }\end{array}$ \\
\hline 1 & $+/-$ & $+/-$ & $+/-$ & $-/-$ & $+/-$ & $-/-$ & $-/-$ \\
\hline 2 & $+/-$ & $+/-$ & $-/-$ & $-/-$ & $+/-$ & $-/-$ & $-/-$ \\
\hline 4 & $+/-$ & $+/-$ & $-/-$ & $-/-$ & $-/-$ & $-/-$ & $-/-$ \\
5 & $+/-$ & $-/-$ & $+/-$ & $+/-$ & $-/-$ & $-/-$ & $-/-$ \\
6 & $+/-$ & $+/-$ & $-/-$ & $+/-$ & $+/-$ & $+/-$ & $+/-$ \\
7 & $+/-$ & $+/-$ & $+/-$ & $+/-$ & $-/-$ & $-/-$ & $-/-$ \\
8 & $+/$ & $-/-$ & $+/-$ & $-/-$ & $-/-$ & $-/-$ & $-/-$ \\
\hline 9 & $+/-$ & $+/-$ & $-/-$ & $+/-$ & $-/-$ & $-/-$ & $-/-$ \\
10 & $+/-$ & $-/-$ & $+/+$ & $+/-$ & $-/-$ & $-/-$ & $-/-$ \\
\hline 11 & $+/-$ & $-/-$ & $+/+$ & $+/-$ & $-/-$ & $-/-$ & $-/-$ \\
12 & $+/-$ & $+/-$ & $+/+$ & $-/-$ & $-/-$ & $-/-$ & $-/-$ \\
\hline 13 & $+/-$ & $+/-$ & $+/+$ & $+/-$ & $+/-$ & $+/-$ & $-/-$ \\
\hline 14 & +- & $+/-$ & $+/+$ & $-/-$ & $+/-$ & $-/-$ & $-/-$ \\
\hline 15 & $+/-$ & $+/-$ & $+/+$ & $-/-$ & $-/-$ & $-/-$ & $-/-$ \\
\hline 16 & $+/-$ & $-/-$ & $-/-$ & $+/-$ & $-/-$ & $+/-$ & $-/-$ \\
\hline 17 & $+/-$ & $-/-$ & $+/-$ & $-/-$ & $-/-$ & $-/-$ & $-/-$ \\
18 & $+/-$ & $-/-$ & $+/+$ & $-/-$ & $-/-$ & $-/-$ & $-/-$ \\
\hline Total & $16 / 0$ & $13 / 0$ & $12 / 8$ & $8 / 0$ & $5 / 0$ & $3 / 0$ & $1 / 0$ \\
\hline
\end{tabular}

Explanations: IHC immunohistochemistry; IF immunofluorescence; + present; - absent
DNA was found in none of the foetuses, $N$. caninum DNA was detected in $26(25.49 \%)$ foetuses (Fig. 1).

Eighteen of the 102 foetuses were determined to contain $N$. caninum by IHC and IF, and most of the immunopositivity was observed in tissues from 16 livers, 13 kidneys and 12 spleens (Tab. 1). In the livers, $N$. caninum antigens were observed more often in the hematopoietic cells than in hepatocytes, kidney tubular epithelial cells and spleen macrophages (Fig. 2). Additional immunopositivity was observed in 8 thymus and 5 brain samples; specifically, in the thymus, stroma, parenchyma, brain glial cells and cytoplasm of the neurons (Fig. 3). Moreover, myocardia in 3 samples and lungs in 1 sample also showed immunopositivity, in the cytoplasm of the myocytes of the myocardium

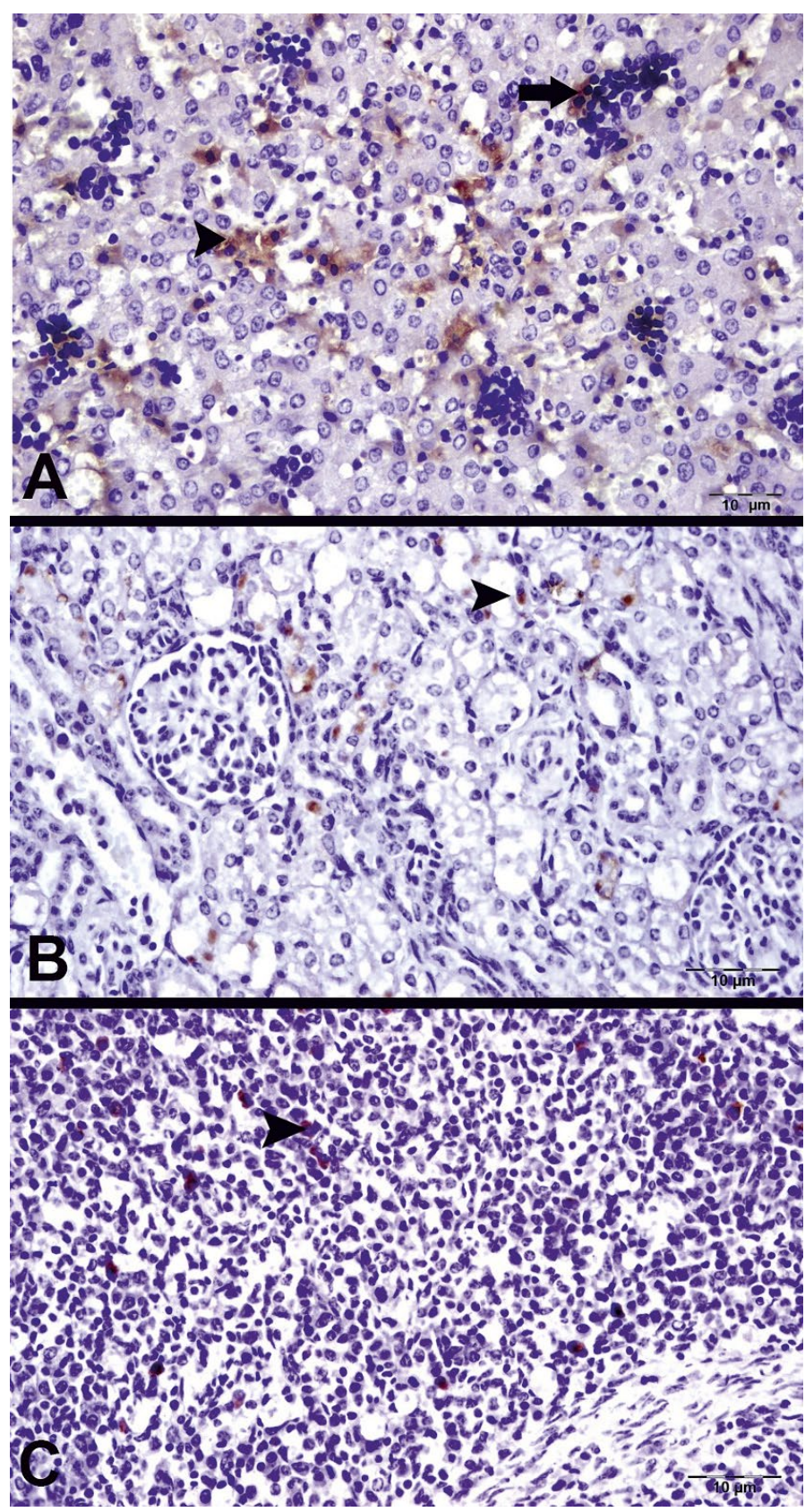

Fig. 2. N. caninum antigens immunpositivity. A. Hepatocytes (arrow) and lymphoid cells (arrowhead) in liver. B. Tubular epithelium (arrowhead) in kidney. C. Macrophages (arrowhead) in spleen 


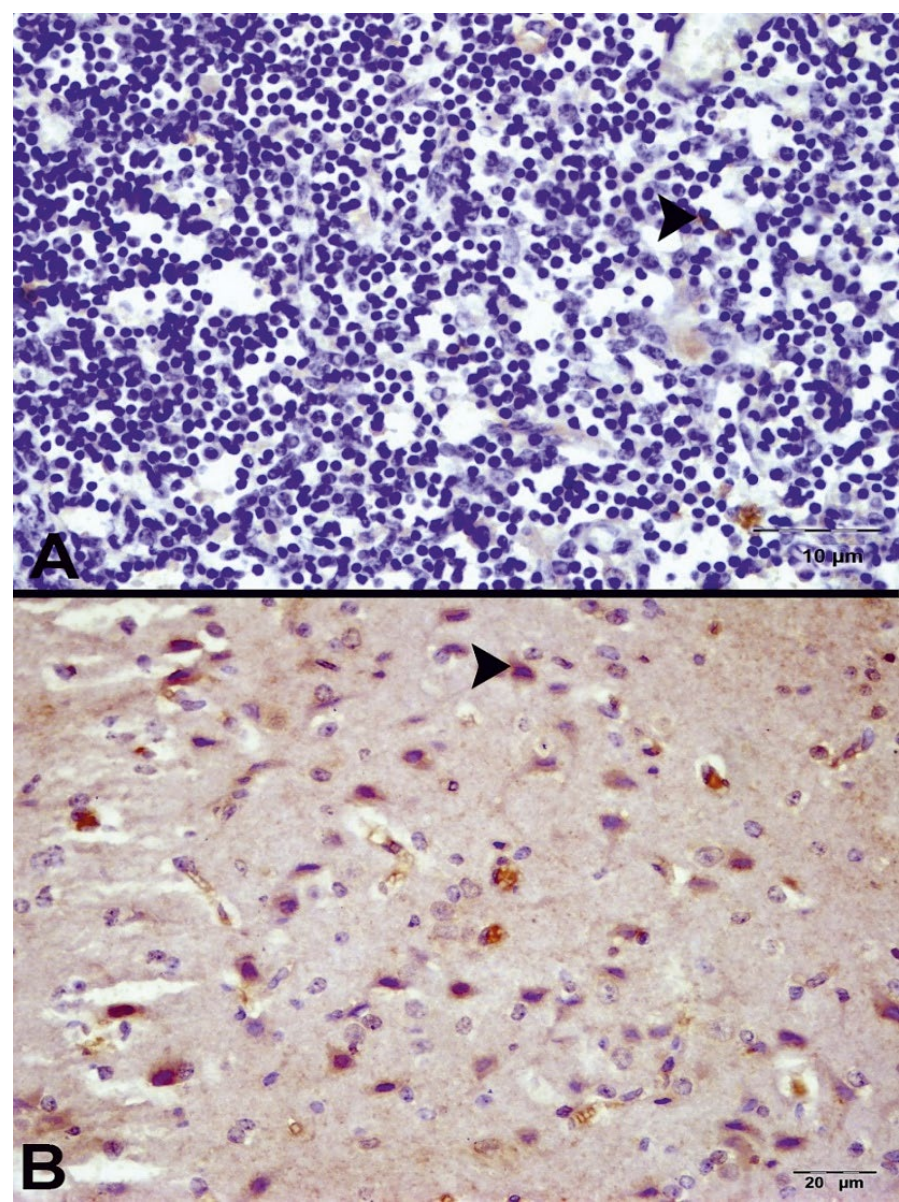

Fig. 3. N. caninum antigens immunpositivity. A. Lymphoid cells (arrowhead) in thymus. B. Neurons (arrowhead) in brain

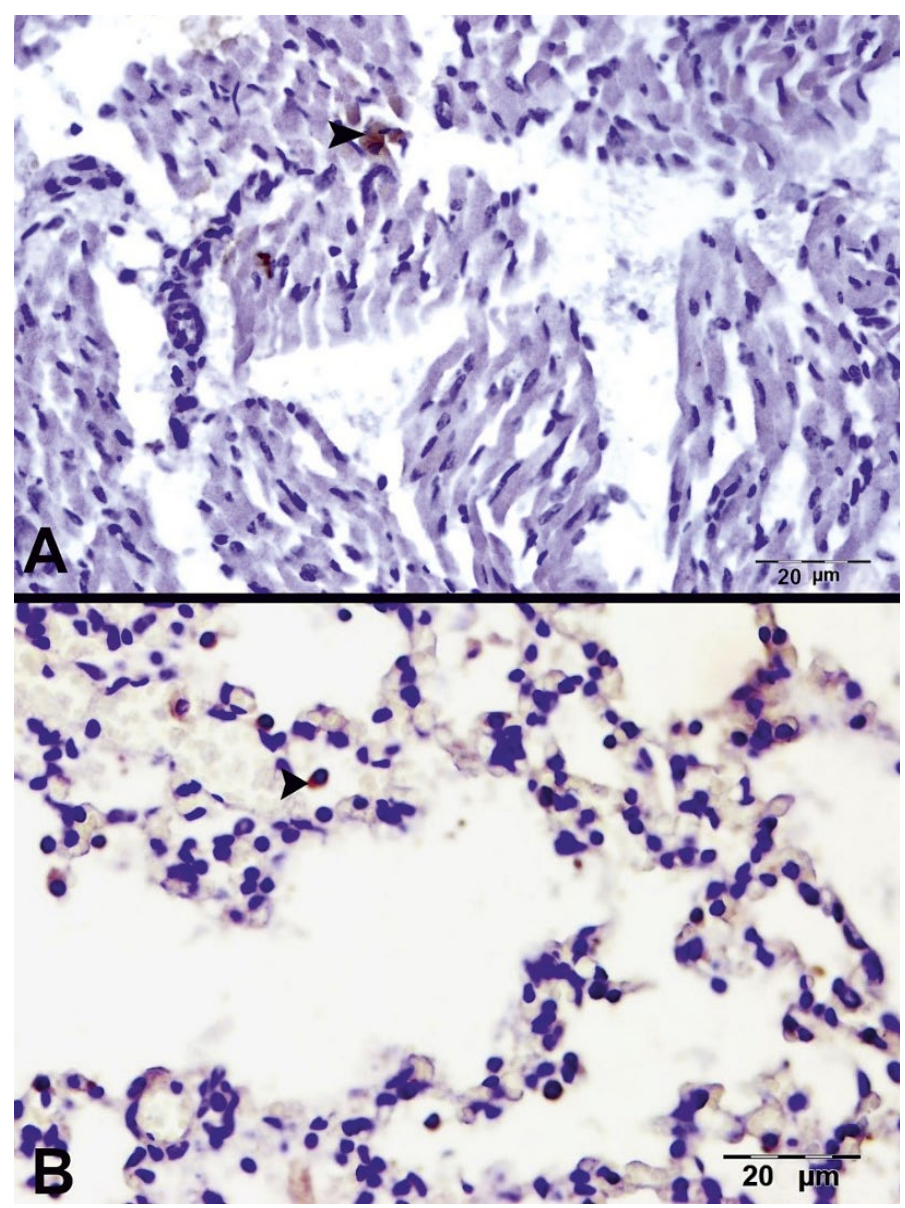

Fig. 4. N. caninum antigens immunpositivity. A. Myocytes (arrowhead) in myocard. B. Lymphoid cells (arrowhead) in lung and the cytoplasm of the lymphoid cells of the lungs (Fig. 4).

The brightest staining of IF was detected in the spleen (Tab. 1). Therefore, IF staining was considered to be the most effective, since sharp border and intrastoplasmic localization of flourescence luminescence were found in spleen cells, and 8 foetuses were evaluated for positive staining. Furthermore, fluorescent staining has the advantage of revealing intracytoplasmic features (Fig. 5). When the IHC and

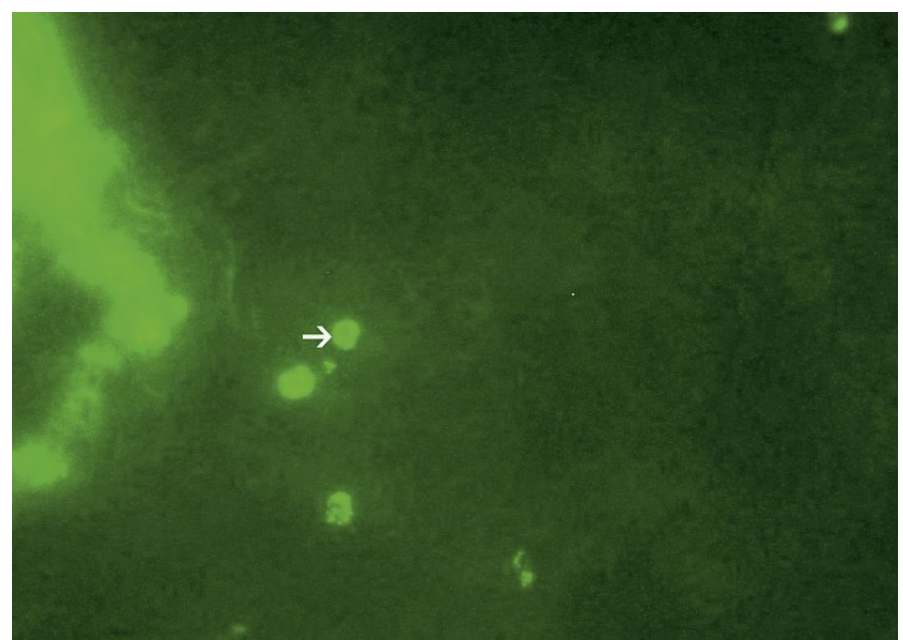

Fig. 5. N. caninum antigens immunofluorescence. Positivity (arrow) in spleen
IF staining results were compared, a statistically significant difference was determined. With IHC staining, immunopositivity was found in tissues of the liver $(\mathrm{n}=16)$, kidney $(\mathrm{n}=13)$, spleen $(\mathrm{n}=12)$, thymus $(\mathrm{n}=8)$, brain $(\mathrm{n}=5)$, myocardium $(\mathrm{n}=3)$ and lungs $(\mathrm{n}=1)$, whereas in IF staining, only spleen tissues $(\mathrm{n}=8)$ showed immunopositivity $(\mathrm{p}<0.001)$.

In this study, we aimed to detect the presence of specific protozoans in aborted bovine foetuses by duplex PCR, IHC and IF, as well as the distribution of the antigens in the organs by IHC and IF. We also compared the IHC and IF results. Overall, in 102 aborted bovine foetuses, $N$. caninum was detected to have $25.49 \%$ positivity using duplex PCR, $17.64 \%$ positivity using IHC and $7.84 \%$ positivity using IF.

T. gondii and N. caninum DNA can be diagnosed by PCR identification $(1,8,23)$, and, studies of the diagnosis of $N$. caninum in aborted bovine foetuses by PCR have been carried out worldwide. For example, $N$. caninum was found positive in $8(38.9 \%)$ out of 21 aborted bovine foetal samples by Paştiu et al. (41) in Romania, in $58(21 \%)$ out of 242 samples by Saager et al. (44) in Sweden, and in $35(80 \%)$ out of 44 samples by Medina et al. (33) in Mexico. In this study, N. caninum was found positive by duplex PCR in $25.49 \%$ of aborted bovine foetuses in Elazı $\breve{g}$, Turkey. The differences between the ratios in the aforementioned studies 
may have resulted from factors such as redundancy, maintenance and hygiene of the population of intermediate carnivorous hosts.

In this study, the detection of $N$. caninum by IHC was $17.64 \%$. There are a number of other studies that diagnosed $N$. caninum by IHC in different countries. These include $19.43 \%$ positivity in Mexico (35), $85 \%$ in Holland (49), 21.3\% in Brazil (39), 8.6\% in Brazil (10), 9.9\% in Argentina (34) and 16.1\% in Sweden (42).

Furthermore, studies done on aborted bovine foetuses by Morales et al. (35) and Wouda et al. (49) were similar in terms of the organs that were examined. Morales et al. (35) found the parasites mostly in the liver; 25 out of 41 foetuses showed $N$. caninum positivity in the liver, 24 in the myocardium and 19 in the brain. Moreover, Wouda et al. (49) found tachyzoites in the brains of all 68 foetuses they examined, in the livers of 21 and in the myocardia of 11 . Pescador et al. (39) showed that the distribution of antigens ranged from maximum to minimum in the brain, liver, kidney, muscle, lung and myocardium, respectively. On the other hand, Cabral et al. (10) found that the distribution of antigens ranged from maximum to minimum in the brain, placenta, heart, liver and kidney, respectively. As stated previously, the density of the $N$. caninum antigens in the organs may differ depending on the infection period of the aborted foetus.

On the basis of IHC testing, the $N$. caninum antigens have been located in necrotic-degenerative neurons, kidneys, cardiomyocytes, Kupffer cells and hepatocytes of the liver, spleen, thymus and macrophages of the lymphoid tissues, such as the lymph nodes (27, $39)$. In the present study, the location of the antigens was similar to that in previous studies.

However, none of the previous studies on aborted bovine foetuses was based simultaneously on duplex PCR, IHC and IF. In addition to PCR, IHC has been accepted as a convenient method for diagnosis; moreover, $7.84 \%$ of $N$. caninum positivity was first found by IF. Although IF has been shown to be convenient in practical use, it has the disadvantage of nonspecific staining results, which leads to diagnostic difficulties. For that reason, the duplex PCR and IHC methods have been found to be preferable in routine laboratory diagnoses.

\section{References}

1. Alkan Z., Özbel Y., Özensoy S., Atambay M.: Moleküler Biyolojik Yöntemler, [in:] Özcel M. A., Altindaş N. (Ed): Parazit Hastalıklarında Tanı, Türkiye Parazitol. Dern. İzmir 1997, p. 15.

2. Amin A. M., Morsy T. A.: Anti-Toxoplasma antibodies in butchers and slaughtered sheep and goats in Jeddah Municipal abattoir, Saudi Arabia. J. Egypt. Soc. Parasitol. 1997, 27, 913-918.

3. Anderson M. L., Andrianarivo A. G., Conrad P. A.: Neosporosis in cattle. Anim. Reprod. Sci. 2000, 417-431.

4. Anderson M. L., Blanchard P. C., Barr B. C., Dubey J. P., Hoffman R. L., Conrad P. A.: Neospora-like protozoan infection as a major cause of abortion in California dairy cattle. J. Am. Vet. Med. Assoc. 1991, 198, 241-244.

5. Barr B. C., Anderson M. L., Blanchard P. C., Daft B. M., Kinde H., Conrad $P$. A.: Bovine fetal encephalitis and myocarditis associated with protozoal infections. Vet. Pathol. 1990, 27, 354-361.

6. Bekele T., Kasali O. B.: Toxoplasmosis in sheep, goats and cattle in central Ethiopia. Vet. Res. Commun. 1989, 13, 371-375.
7.Bowman D. D., Lynn R. C., Eberhard M. L.: Georgis' Parasitology for Veterinarians. Elsevier, Science 2003.

8. Buxton D.: Protozoan infections (Toxoplasma gondii, Neospora caninum and Sarcocystis spp.) in sheep and goats: recent advances. Vet. Res. 1998, 29 , 289-310.

9. Cabaj W., Choromański L., Rodgers S., Moskwa B., Malczewski A.: Neospora caninum infections in aborting dairy cows in Poland. Acta Parasitol. 2000, 45, 113-114.

10. Cabral A. D., Camargo C. N., Galleti N. T. C., Okuda L. H., Pituco E. M. Del Fava C.: Diagnosis of Neospora caninum in bovine fetuses by histology, immunohistochemistry, and nested-PCR. Rev. Bras. Parasitol. Vet. 2009, $18,4$.

11. Cabral A. D., Camargo C. N., Galleti N. T. C., Okuda L. H., Pituco E. M., Del Fava C.: Screening for Toxoplasma gondii in aborted bovine fetuses in Brazil. Arq. Inst. Biol. 2013, 80, 103-105.

12. Canada N., Meireles C. S., Rocha A., Correia Da Costa J. M., Erickson M. $W$., Dubey J. P.: Isolation of viable Toxoplasma gondii from naturally infected aborted bovine fetuses. J. Parasitol. 2002, 88, 1247-1248.

13. Chabra M. B., Gupta S. L., Gautam O. P.: Toxoplasma seroprevalance in animals in Northern India. Int. J. Zoonoses. 1985, 12, 136-142.

14.Davison H. C., Otter A., Trees A. J.: Significance of Neospora caninum in British dairy cattle determined by estimation of seroprevalence in normally calving cattle and aborting cattle. Int. J. Parasitol. 1999, 29, 1189-1194.

15. Dubey J. P.: Recent advances in Neospora and neosporosis. Vet. Parasitol. 1999, 84, 349-367.

16. Dubey J. P.: Review of Neospora caninum and neosporosis in animals. Korean J. Parasitol. 2003, 41, 1-16.

17. Dubey J. P., Barr B. C., Barta J. R., Bjerkas I., Björkman C., Blagburn B. L., Bowman D., Buxton D., Ellis J. T., Gottstein B., Hemphill A., Hill D. E., Howe D. K., Jenkins M. C., Kobayaski Y., Koudela B., Marsh A. E., Mattsson J. G., McAllister M. M., Modry D., Omata Y., Sibley L. D., Speer C. A., Trees A. J., Uggla A., Upton S. J., Williams D. J. L., Lindsay D. S.: Redescription of Neospora caninum and its differentiation from related coccidian. Int. J. Parasitol. 2002, 32, 929-946.

18. Dubey J. P., Beattie C. P.: Toxoplasmosis of Animal and Man. CRC Press 1988, p. 61-80.

19.Dubey J. P., Buxton D., Wouda W.: Pathogenesis of bovine neosporosis. J. Comp. Pathol. 2006, 134, 267-289.

20.Dubey J. P., Dorough K. R., Jenkins M. C., Liddell S., Speer C. A., Kwok $O$. C. H., Shen $S$. K.: Canine neosporosis clinical signs, diagnosis, treatment, treatment and isolation of Neospora caninum in mice and cell culture. Int. J. Parasitol. 1998, 28, 1293-1304.

21. Dubey J. P., Lindsay D. S.: A review of Neospora caninum and neosporosis Vet. Parasitol. 1996, 67, 1-59.

22. Dubey J. P., Schares G.: Diagnosis of bovine neosporosis. Vet. Parasitol. 2006, $140,1-2$.

23.Dumanli N., Aktaş M.: Toxoplasmatidae (Toxoplasma, Neospora), [in:] Dumanli N., Karaer Z. (ed.): Veteriner Protozooloji. 2010, p. 119-136.

24. Georgieva D. A., Prelezov P. N., Koinarski V. T. S.: Neospora caninum and neosporosis in animals - A review. Bulgarian J. Vet. Med. 2006, 9, 1-26.

25. Hemphill A.: The host-parasite relationship in neosporosis. Adv. Parasitol. 1999, 43, 47-104.

26. Kaufmann J.: Parasitic infections of domestic animals. A diagnostic manual. Birkhause Verlag 1996, p. 423.

27. Kul O.: Epidemiology and Pathogenesis of Neospora caninum Infection: Special Emphasis to Neosporosis Status of Turkey. Animal Health, Production and Hygiene 2012, 1, 70-79.

28. Levine N. D.: Veterinary Protozoology. Iowa State University Press 1985 , p. 413.

29. Lindsay D. S., Dubey J. P.: Immunohistochemical diagnosis of Neospora caninum in tissue sections. Am. J. Vet. Res. 1989, 50, 1981-1983.

30. Lindsay D. S., Dubey J. P., McAllister M.: Neospora caninum and the potential for parasite transmission. Small Animal. 1999, 21, 317-320.

31. Masala G., Porcu R., Madau L., Tanda A., Ibba B., Sata G., Tola S.: Survey of ovine and caprine Toxoplasmosis by IFAT and PCR assays in Sardina, Italy. Vet. Parasitol. 2003, 117, 15-21.

32. McAllister M. M., Dubey J. P., Lindsay D. S., Jolley W. R., Wills R. A., McGuire A. M.: Dogs are definitive hosts of Neospora caninum. Int. J. Parasitol. 1998, 28, 1473-1478.

33. Medina L., Cruz-Vázquez C., Quezada T., Morales E., García-Vázquez Z.: Survey of Neospora caninum infection by nested PCR in aborted fetuses from dairy farms in Aquascalientes, Mexico. Vet. Parasitol. 2006, 136, 187-191.

34. Moore D. P., Regidor-Cerrillo J., Morrell E., Poso M. A., Cano D. B., Leunda M. R., Linschinky L., Odeón A. C., Odriozola E., Ortega-Mora L. M., Campero C. M.: The role of Neospora caninum and Toxoplasma gondii in spontaneous bovine abortion in Argentina. Vet. Parasitol. 2008, 156, 163-167.

35. Morales E., Trigo F. J., Ibarra F., Puente E., Santa Cruz M.: Neosporosis in Mexican Dairy Herds: Lesions and Immunohistochemical Detection of Neospora caninum in Fetuses. J. Comp. Pathol. 2001, 125, 58-63. 
36. Naguleswaran A., Hemphill A., Rajapakse R. P. V.J., Sager H.: Elaboration of a crude antigen ELISA for serodiagnosis of caprine Neosporosis: validation of the test by detection of Neospora caninum-specific antibodies in goats from Sri Lanka. Vet. Parasitol. 2004, 126, 257-262.

37. O'Donoghue J. P., Riley M. J., Clarke J. F.: Serological survey for Toxoplasma infections in sheep. Aust. Vet. J. 1987, 64, 40-45.

38. Odriozola H., Bretschneider G., Poso M. A.: Neospora caninum associated abortion in a dairy herd in Argentina. Vet. Rec. 1998, 143, 228-229.

39. Pescador C. A., Corbellini L. G., Oliveira E. C., Raymundo D. L., Driemeier D. Histopathological and immunohistochemical aspects of Neospora caninum diagnosis in bovine aborted foetuses. Vet. Parasitol. 2007, 150, 159-163.

40. Quintanilla-Gozalo A., Pereira-Bueno J., Tabares E., Innes E. A., GonzalezPaniello R., Ortega-Mora L. M.: Seroprevalence of Neospora caninum infection in dairy and beef cattle in Spain. Int. J. Parasitol. 1999, 29, 1201-1208.

41. Paştiu O. Ş. A., Adriana Györke A., Cozma V.: Molecular detection of Neospora caninum abortion in dairy cattle from different historical regions of Romania. Sci. Parasitol. 2012, 13, 159-162.

42. Reitt K., Hilbe M., Voegtlin A., Corboz L., Haessig M., Pospischil A.: Aetiology of Bovine Abortion in Switzerland from 1986 to 1995 - A Retrospective Study with Emphasis on Detection of Neospora caninum and Toxoplasma gondii by PCR. J. Vet. Med. 2007, 54, 15-22.

43. Rommel M.: Protozoenifektionen der Wiederkaufer, [in:] Rommel M., Eckert J., Kutzer E., Körting W., Schneider T. (eds.): Veterinärmedizinische Parasitologie 5. Blackwell Wissenschafts-Verlag 2001, p. 121-191.
44. Sager H., Fischer I., Furrer K., Strasser M., Waldvogel A., Boerlin P., Audigé L., Gottstein B. A.: Swiss case-control study to assess Neospora caninum-associated bovine abortions by PCR, histopathology and serology. Vet. Parasitol. 2001, 102, 1-15.

45. Soulsby E. L. J.: Helminths. Arthropods and Protozoa of Domesticated Animals. Bailliere Tindall 1986, p. 809

46. Tenter A. M., Heckeroth A. R., Weiss L. M.: Toxoplasma gondii: from animals to humans. Int. J. Parasitol. 2000, 30, 1217-1258.

47. Tramuta C., Lacerenza D., Zoppi S., Goria M., Dondo A., Ferroglio E., Nebbia P., Rosati S.: Development of a set of multiplex standard polymerase chain reaction assays for the identification of infectious agents from aborted bovine clinical samples. J. Vet. Diagn. Invest. 2011, 23, 657-664.

48. Vazquez Z. G., Vazquez C. C., Espinosa L. M., Tapia D. G., Martinez B. C. Serological survey of Neospora caninum infection in dairy cattle herds in Aquascalientes, Mexico. Vet. Parasitol. 2002, 106, 115-120.

49. Wouda W., Moen A. R., Visser I. J. R., Van Knapen F.: Bovine fetal neosporosis: a comparison of epizootic and sporadic abortion cases and different age classes with regard to lesion severity and immunohistochemical identification of organisms in brain, heart, and liver. J. Vet. Diagn. Invest. 1997, 9, 180-185.

50. Zhai Y. Q., Zhao J. P., Zhu X. Q., Li L., Wrang C. R.: Research advances in the diagnosis of cattle neosporosis. J. Anim. Vet. Adv. 2007, 6, 1377-1387.

Corresponding author: Yrd. Doc. Dr. Mustafa Özkaraca, Department of Pathology, Faculty of Veterinary Medicine, Atatürk University, 25240 Erzurum, Turkey; e-mail: mustafa.ozkaraca@atauni.edu.tr 